\title{
Cinsel İstismara Uğrayan Çocuk ve Ergenlerin Sosyodemografik Özellikleri ve Ruhsal Değerlendirmesi
}

\section{Psychiatric Disorders and Sociodemographic Characteristics of Sexually Abused Children and Adolescents}

\author{
Ŭ̆ur Koçak ${ }^{1}$, Ahmet Hamdi Alpaslan ${ }^{2}$ \\ ${ }^{1}$ Afyon Kocatepe Üniversitesi Tip Fakültesi Adli Tip Anabilim Dalı \\ ${ }^{2}$ Afyon Kocatepe Üniversitesi Tip Fakültesi Çocuk ve Ergen Psikiyatrisi Anabilim Dalı
}

\section{Özet}

Amaç: Çalışmamızın amacı cinsel istismara maruz kaldığ 1 bildirilen çocuk ve ergen olguların sosyodemografik özelliklerinin ve ruhsal bozukluk tanılarının belirlenmesidir.

Gereç ve Yöntem: Bu çalışmada Kasım 2012 ile Mayıs 2014 tarihleri arasında Afyon Kocatepe Üniversitesi Tip Fakültesi Çocuk ve Ergen Psikiyatri Polikliniğine adli rapor düzenlenmesi amacıyla gönderilen ve cinsel istismara maruz kaldığ olguların ( $n=158)$ bilgileri geriye dönük olarak incelenmiştir. Adli olguların sosyodemografik özellikleri, psikiyatrik tanıları, zekâ düzeyleri, adli istekler ve istismarcı-mağdur ilişkisinin özellikleri poliklinik dosyalarından elde edilmiştir. Değerlendirilen olgulara DSM-IVTR tanı ölçütlerine göre tanı konulmuştur.

Bulgular: Araştırmaya katılan 158 olgunun \%17,7'sini ( $n=28)$ erkek, \%82,3’ünü (n=130) kız olgular oluşturmaktaydı. Olguların yaşları 6 ile 18 arasında değişmekte olup ortalaması $13,94(\mathrm{sd} \pm 2,56)$ bulunmuştur. Vajinal penetrasyon \%32,5 ile mağdurlar tarafindan en sık bildirilen istismar tipi iken, bunu sırasıly bedene cinsel amaçla dokunma $(\% 29,9)$, anal penetrasyon $(\% 22,3)$ ve diğerleri izlemekteydi. Mağdurların DSM-IV TR tanı ölçütlerine göre aldıkları tanılar incelendiğinde; olguların \%24,1'ine $(\mathrm{n}=38)$ travma sonrası stres bozukluğu (TSSB), \%20,9'una ( $\mathrm{n}=33)$ depresif bozukluk, \%19'una $(\mathrm{n}=30)$ ise akut stres bozukluğu (ASB) tanısı konulduğu, \%36,1'inin $(n=57)$ herhangi bir ruhsal bozukluk tanısı almadığı belirlenmiştir.

Sonuç: Çocuk cinsel istismarı sılklı̆ı tüm dünyada oldŭgu gibi ülkemizde de korkutucu bir hızla artmaktadır. Bulgularımız, cinsel istismara uğrayan çocuk ve ergenlerin ortaya çıkarılması için disiplinler arası kapsamlı araştırma ve değerlendirme çalışmalarına ihtiyaç olduğunu göstermektedir.

Anahtar kelimeler: Çocuk, Ergen, Cinsel istismar, Sosyodemografik özellikler.

\section{Giriş}

Çocuk istismarı; çocuklara bir yetişkin, toplum, devlet veya başka bir çocuk tarafından; bedensel, duygusal, zihinsel veya sosyal gelişimlerini olumsuz etkileyen kasıtlı bir davranış uygulanmasidır (1). Cinsel istismar (CI) ise, henüz cinsel gelişimini tamamlamamış bir çocuğun ya da ergenin, bir erişkin tarafından cinsel arzu ve gereksinimlerini karşılamak

Sorumlu Yazar: Uğur Koçak

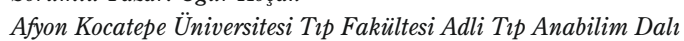

E-mail: ukocak@gmail.com

\section{Abstract}

Objective: In this study, it was aimed to determine sociodemographic characteristics and psychiatric diagnoses of sexually abused children and adolescents.

Materials and Methods: The data of the sexually abused children and adolescents ( $n=158)$ who were referred to the Afyon Kocatepe University Medical Faculty, Department of Child and Adolescent Psychiatry for a forensic report between October 2012 and May 2014 were examined retrospectively. The socio-demographic characteristics, psychiatric diagnoses, mental statuses, juridical requests, and abuser-victim relationships of the forensic cases were collected from the outpatient medical records. The cases were diagnosed using DSM-IVTR criteria.

Results: Of the 158 cases included in the study, $17.7 \%(\mathrm{n}=28)$ was male and $82.3 \%(\mathrm{n}=130)$ was female. Their age varied between 6 and 18 years, with a mean of $13.94(\mathrm{sd} \pm 2.56)$ years. Vaginal penetration was the most reported type of abuse with a rate of $32.5 \%$, followed by sexual touching (29.9\%), anal penetration (22.3\%) and the others. When the psychiatric diagnoses of the cases were analyzed, post traumatic stress disorder (PTSD) was the most common diagnosis with a rate of $24.1 \%$, followed by depressive disorder (20.9\%), and acute stress disorder (19.0\%) respectively, $36.1 \%$ of the cases had no psychiatric diagnosis.

Conclusion: The incidence rate of child sexual abuse is increasing alarmingly in our country such as in the world. Our findings suggest that broader interdisciplinary research is needed to reveal child and adolescent sexual abuse.

Keywords: Child, Adolescent, Sexual abuse, Sociodemographic characteristics. için güç kullanarak, tehdit ya da kandırma yolu ile kullanılması olarak tanımlanmaktadır (2).

Cinsel istismar davranışı dokunma veya penetrasyon şeklinde olabilir. Bunun yanı sıra cinsel içerikli konuşma, teşhircilik, röntgencilik gibi temas içermeyen davranışlar da cinsel istismar kavramı içerisinde değerlendirilmektedir. Ayrica, çocuk fuhuşu ve çocuk pornografisi cinsel sömürü tanımı altında, çocuğa biyolojik olarak akrabalığı olan ve kanunen evlenmeleri yasak olan aile bireylerinin cinsel istismarı ise ensest tanımı altında yer almaktadır $(3,4)$.

Çocuklara yönelik cinsel istismar sıklı̆̆ı tüm dünyada hızla 
artmaktadır. Çalışmalarda çocuklukta cinsel istismara maruz kalma sıklığının \%10-40 arasında değiştiği ve cinsel istismar kurbanlarının \% 53' ünün 14 yaşın altında olduğu bildirilmektedir $(5,6)$. Literatürde istismarcıların çoğunluğunun erkek, cinsel istismara uğrayanların çoğunluğun ise kız cinsiyette olduğu bildirilmektedir (7). Ayrıca, cinsel istismarda çocuk için birçok sosyodemografik olarak değerlendirilebilecek risk etmeni söz konusudur. Ancak, bunlar arasında en önemli rol oynayan ailesel etmenlerdir. Düşük sosyoekonomik düzey, anne ve baba arasındaki iletişim sorunları, boşanmış anne-baba varlığı cinsel istismar riskini artırmaktadır. Aile bireylerinde, özellikle ebeveynlerde gözlenen ruhsal bozukluklar, ebeveynlerde fiziksel, duygusal ve cinsel istismar öyküsü varlığı risk olarak bildirilmiştir. Anne ve babada alkol madde kullanımı da cinsel istismar için risk olarak değerlendirilmektedir. Anne babanın eğitim düzeyinin düşük olması hem istismar riskini hem de istismar sonrası ruhsal bozukluk gelişim riskini arttırmaktadır $(8,9)$.

Cinsel istismara maruz kalan çocuklar sıklıkla adli süreç içerisinde ya da ebeveynleri tarafından istismarın neden olduğu bedensel ya da ruhsal belirtiler nedeniyle çocuk ve ergen psikiyatrisi kliniklerine başvururlar. Cİ olgularına özgü bir ruhsal bozukluk tanımlanmamakla birlikte istismarın ruhsal bozukluk sıklığını arttırdığı, istismara uğrayan çocuk ve ergenlerde yaşamın ilerleyen dönemlerinde birçok ruhsal bozukluğun ortaya çıktığı bildirilmektedir $(10,11)$. İstismara bağlı olarak gelişen ruhsal belirtiler çocuklarda dalgalı bir seyir gösterebilir ve bu belirtiler olaydan yıllar sonra da ortaya çıkabilir (7). Çocuklarda cinsel istismar sonucunda kaygı bozuklukları, dissosiyatif yaşantılar, kendine zarar verme ve intihar davranışları, uyku bozuklukları, duygudurum bozuklukları, anksiyete bozuklukları, travma sonrası stres bozukluğu (TSSB), davranım bozuklukları, ve yeme bozuklukları görülebilir (12).

Çocuk ve ergenlerin adli psikiyatrik değerlendirmesi, mahkeme karar süreci için bilgi sağlama ve bilirkişiliği içerdiği gibi, olası psikiyatrik bozuklukların saptanması ve çocuğun korunabilmesi için de önem arz etmektedir. Bu çalışmada amacımız adli mercilerce Afyon Kocatepe Üniversitesi Tıp Fakültesi Çocuk ve Ergen Psikiyatrisi polikliniğine rapor düzenlenmesi amacıyla gönderilen cinsel istismar mağdurlarının ruhsal durumlarını, sosyodemografik özelliklerini yanı sıra zanlının özelliklerini incelenmektir.

\section{Gereç ve Yöntem}

Afyon Kocatepe Üniversitesi Tıp Fakültesi Çocuk ve Ergen Psikiyatrisi polikliniğine Kasım 2012 ile Mayıs 2014 tarihleri arasında adli rapor düzenlenmesi amacıyla gönderilen, cinsel istismara maruz kalmış çocuk ve ergen olguların $(n=158)$ bilgileri geriye dönük olarak incelenmiştir. Adli olguların psikiyatrik tanıları, zekâ düzeyleri, adli istekler ve istismarcımağdur ilişkisinin özellikleri poliklinik dosyalarından elde edilmiştir. Değerlendirilen olgulara DSM-IV TR tanı ölçütlerine göre tanı konulmuştur.

\section{İstatistiksel analiz}

Analizlerde SPSS 19.00 İstatistiksel Paket Programı tanımlayıcı istatistik testleri kullanılarak çalışmadaki demografik verilerin frekans analizi yapılmış, sayı, dağılım ve yüzde değerleri hesaplanmıştır. Veriler ortalama değer, standart sapma ve yüzde olarak verilmiştir.

\section{Bulgular}

Araştırmaya katılan ve yaşları 6 ile 18 arasında değişen 158 olgunun yaş ortalaması $13,94(\mathrm{sd} \pm 2,56)$ olup \%17,7'sini $(\mathrm{n}=28)$ erkek, \%82,3’ünü (n=130) kız olgular oluşturmaktaydı. Erkek olguların yaş ortalaması $12,24(\mathrm{sd} \pm 2,77), \mathrm{k} ı$ olguların yaş ortalaması 14,30 ( $\operatorname{sd} \pm 2,36)$ olup yaşları 6 ile 18 arasında değişmekte idi. Okul çağındaki olguların eğitim durumları incelendiğinde; 2 (\%1,3) çocuğun okula gitmediği, $1(\% 0,6)$ çocuğun sadece özel eğitim aldığı, $31(\% 19,6)$ çocuğun ilköğretimi bitirmeden okulu terk ettiği, $66(\% 41,8)$ çocuğun ilköğretime devam ettiği, 5 (\%3,2) çocuğun ilköğretim mezunu olduğu, 18 (\%11,4) çocuğun ise liseye devam ettiği belirlenmiştir. Olgularda sigara kullanım oranı \%27,4 ( $n=43)$, alkol kullanım oranı \%9,6 ( $\mathrm{n}=15)$ iken madde kullanım oranı $\% 5,7(n=9)$ olarak bulunmuştur (Tablo 1 ).

Cinsel istismar tipleri incelendiğinde; vajinal penetrasyon \%32,5 ile mağdurlar tarafından en sık bildirilen istismar tipi iken, bunu sırasıyla bedene cinsel amaçla dokunma $(\% 29,9)$, anal penetrasyon $(\% 22,3)$ ve diğerleri izlemekteydi. Olguların $\% 5,7$ 'sinde $(n=9)$ sözlü sataşma, \%3,2'sinde (n=5) fuhuşa sürükleme, $\% 3,2$ 'sinde $(n=5)$ 1rza tasaddi olayı meydana geldiği bildirilmiştir. Olgulardan \%51,9'unda ( $\mathrm{n}=82$ ) birden fazla cinsel istismar olayı meydana geldiği, \%61,4 (n=94) ile en yüksek oranda istismarcının aile dışından bir tanıdık olduğu, olgulardan \%53,2'sinin (n=84) zorlama veya şiddete maruz kaldığı bildirilmiştir (Tablo 2).

Olguların tanıları ruhsal değerlendirme sonrası DSM-IV TR tanı kriterlerine göre konulmuştur; mağdurların \%24,1'ine ( $n=38)$ TSSB, \%20,9'una ( $n=33$ ) depresif bozukluk, \%19'una ( $n=30)$ ise akut stres bozukluğu tanısı konduğu, \%36,1’inin ( $n=57)$ herhangi bir ruhsal bozukluk tanısı almadığı belirlenmiştir. Komorbid ruhsal bozukluklar yönünden yapılan değerlendirmede; olguların \%15,2'sinde $(n=24)$ depresif bozukluk, \%2,5'inde $(\mathrm{n}=4)$ davranım bozukluğu, \%0,6'sında $(n=1)$ panik bozukluk, yine $\% 0,6$ 'sında $(n=1)$ enürezis nokturna tanısı konduğu, \%81'inin ( $\mathrm{n}=128)$ komorbid ruhsal bozukluk 
Tablo 1. Olguların sosyodemografik özellikleri.

\begin{tabular}{|c|c|c|}
\hline \multicolumn{3}{|l|}{ Cinsiyet } \\
\hline Erkek & 28 & 82,3 \\
\hline Kız & 130 & 17,7 \\
\hline \multicolumn{3}{|l|}{ Eğitim durumu } \\
\hline Okul yaşında ancak hiç okula gitmemiş & 2 & 1,3 \\
\hline Sadece özel eğitime gidiyor & 1 & 0,6 \\
\hline İlköğretim bitirmeden terk & 31 & 19,6 \\
\hline İlk öğretime devam ediyor & 66 & 41,8 \\
\hline İlköğretim mezunu & 5 & 3,2 \\
\hline Lise bitirmeden terk & 18 & 11,4 \\
\hline Liseye devam ediyor & 34 & 21,5 \\
\hline Lise mezunu & 1 & 0,6 \\
\hline \multicolumn{3}{|l|}{ Kiminle yașıyor } \\
\hline Anne ve baba & 90 & 57,0 \\
\hline Anne ile & 33 & 20,9 \\
\hline Baba ile & 14 & 8,9 \\
\hline Akrabalarının yanında & 8 & 5,1 \\
\hline Kurumda & 13 & 8,2 \\
\hline \multicolumn{3}{|l|}{ Aile tipi } \\
\hline Çekirdek aile & 85 & 53,8 \\
\hline Dağılmış aile & 45 & 28,5 \\
\hline Ebeveynlerden biri vefat etmiş & 7 & 4,4 \\
\hline Geniş aile & 21 & 13,3 \\
\hline \multicolumn{3}{|l|}{ Sosyoekonomik düzey } \\
\hline Düşük & 97 & 61,4 \\
\hline Orta & 58 & 36,7 \\
\hline Yüksek & 3 & 1,9 \\
\hline \multicolumn{3}{|l|}{ Sigara kullanımı } \\
\hline Var & 43 & 27,4 \\
\hline Yok & 114 & 72,6 \\
\hline \multicolumn{3}{|l|}{ Alkol kullanımı } \\
\hline Var & 15 & 9,6 \\
\hline Yok & 142 & 90,4 \\
\hline \multicolumn{3}{|l|}{ Madde kullanımı } \\
\hline Var & 9 & 5,7 \\
\hline Yok & 148 & 94,3 \\
\hline
\end{tabular}

tanısı almadığı belirlenmiştir (Tablo 3).

Klinik olarak şüphelenilen olgulara WISC-R testi uygulanarak zeka düzeyleri belirlenmiştir. Zekâ düzeyi 136
(\%86,1) olguda normal, 21 (\%13,3) olguda hafif düzeyde olup, 1 $(\% 0,6)$ olguda orta düzeyde mental retardasyon tespit edilmiştir (Tablo 4). 
Tablo 2. Cinsel istismar tipleri ve istismarcı özellikleri.

\begin{tabular}{|c|c|c|}
\hline \multirow{2}{*}{\multicolumn{3}{|c|}{ İstismar tipleri }} \\
\hline & & \\
\hline Bedene cinsel amaçla dokunma & 47 & 29,9 \\
\hline Irza tasaddi (petting) & 5 & 3,2 \\
\hline Vajinal penetrasyon & 51 & 32,5 \\
\hline Anal penetrasyon & 35 & 22,3 \\
\hline Fuhuşa sürükleme & 5 & 3,2 \\
\hline Sözlü sataşma & 9 & 5,7 \\
\hline Teşhircilik & 4 & 2,5 \\
\hline Porno içerikli video izletme & 1 &, 6 \\
\hline \multicolumn{3}{|l|}{ İstismar sayısı } \\
\hline Bir & 76 & 48,1 \\
\hline Birden fazla & 82 & 51,9 \\
\hline \multicolumn{3}{|l|}{ İstismarcı sayısı } \\
\hline Bir & 128 & 81,0 \\
\hline Birden fazla & 30 & 19,0 \\
\hline \multicolumn{3}{|l|}{ İstismarcının yakınlığı } \\
\hline Aile içi & 20 & 12,7 \\
\hline Geniş aile & 5 & 3,2 \\
\hline Aile dıșı tanıdık & 97 & 61,4 \\
\hline Yabancı & 36 & 22,8 \\
\hline \multicolumn{3}{|l|}{ İstismarcının cinsiyeti } \\
\hline Erkek & 156 & 98,7 \\
\hline Kadın & 2 & 1,3 \\
\hline \multicolumn{3}{|l|}{ Zorlama ve şiddet } \\
\hline Var & 84 & 53,2 \\
\hline Yok & 74 & 46,8 \\
\hline \multicolumn{3}{|l|}{ Başka mağdur varlığı } \\
\hline Var & 22 & 13,9 \\
\hline Yok & 136 & 86,1 \\
\hline
\end{tabular}

Tablo 3. Cinsel istismar sonrası psikiyatrik tanılar.

\begin{tabular}{|c|c|c|}
\hline Ruhsal bozukluk tanıları & 57 & 36,1 \\
Yok & 30 & 19,0 \\
ASB & 38 & 24,1 \\
TSSB & 33 & 20,9 \\
Depresif bozukluk & & \\
Komorbid ruhsal bozukluk tanıları & 128 & 81,0 \\
Yok & 24 & 15,2 \\
Depresif bozukluk & 4 & 2,5 \\
Davranım bozukluğu & 1 &, 6 \\
Panik bozukluk & 1 &, 6 \\
Enürezis nokturna & & \\
\hline
\end{tabular}

ASB: Akut stres bozukluğu

TSSB: Travma sonrası stres bozukluğu 
Tablo 4. Cinsel istismara uğrayan olguların zekâ düzeyleri.

\begin{tabular}{|c|c|c|}
\cline { 2 - 3 } \multicolumn{1}{c|}{} & $\mathbf{n}$ & $\mathbf{\%}$ \\
\hline Zeka Düzeyi & & \\
Normal & 136 & 86,1 \\
Hafif MR & 21 & 13,3 \\
Orta MR & 1 &, 6 \\
\hline
\end{tabular}

\section{Tartışma}

Çocuğun cinsel istismarı fiziksel, duygusal, sosyal, ahlaki, kültürel ve hukuki boyutları olan geniş kapsamlı ve karmaşık bir sorundur. Yapılan çalışmalarda, cinsel istismara uğrayan olguların çoğunluğunu kız çocukların oluşturduğu ve kızların erkeklere göre istismar edilme oranının 2-9 kat daha fazla olduğu bildirilmektedir (13-19). Ülkemizde Erdoğan ve ark.'nın (2011) yaptığı çalışmada mağdurların \% 71,6'sı, Vural ve ark.'nın (2014) yaptığı çalışmada ise mağdurların \% 80’inin kız cinsiyetten oldukları saptanmıştır $(6,7,20)$. Çalışmamızdaki \%82,3 olgunun kızlardan oluşması, kız çocuklarının daha fazla cinsel istismara maruz kaldığ 1 bilgisini desteklemektedir, ancak son yıllardaki yayınlar erkek çocuklarda da istismar sıklığının ve etkisinin artışına dikkat çekmektedir (12).

Ülkemizde yapılan bir çalışmada (Bursa) çocuk psikiyatrisine başvuran istismar olgularında ortalama yaş 13,76 olarak bildirilmiştir (20). Bizim çalışmamızda da benzer şekilde cinsel istismara uğrayanların ortalama yaşı 13,94 olarak belirlenmiştir. Ergenlerin cinsel istismar konusunda algılarının ve farkındalıklarının, istismar eyleminin ahlaki redaetini idrak yeteneklerinin çocuğa göre daha yüksek olması bildirimde bulunma oranlarının da yükselmesine neden olmuş olabilir.

Ülkemizde yapılan çalışmalarda istismarların \%66,3-78,0'ının tanıdık birisi veya akrabalar tarafından gerçekleştirildiği gösterilmiştir $(6,18,21)$. Literatürde, çocukların cinsel istismarında, istismarda bulunanların \%6085’inin akrabalar, öğretmenler, komşular, otorite figürleri gibi çocuğun bildiği ve güvendiği kişiler olduğu saptanmıştır $(20,22,23)$. Çalışmamızda da, cinsel istismarın \%77,2'sinin aile bireyleri, akraba veya aile dışında tanıdık kişiler tarafından gerçekleştirildiği saptanmıştır. Ayrıca, literatürde günümüze kadar bildirilen araştırmaların sonuçlarına benzer şekilde bizim çalışmamızda da çocuklara cinsel istismarda bulunanların tamamına yakınının erkek olduğu görülmektedir $(\% 98,7)$. Bu bulgumuzun, kadınlar tarafından yapılan tacizlerin genel olarak daha düşük oranda bildirilebildiği gerçeği ile birlikte değerlendirilmesini öneriyoruz $(24,25)$.

Cinsel istismara uğrayan olgularımızın \%13,9'unda hafif ya da orta derecede zekâ geriliği bulunduğu saptanmıştır. Zekâ geriliğinde ve sınır zekâ düzeyinde algılama ve muhakeme becerileri kısıtlı olduğundan, bu bireylerin istismara uğrama riskinin daha fazla olduğu bildirilmektedir (26). Ayrıca zekâ geriliği olan çocuklar olayı değerlendirirken ve yetkili bir kişiye bildirirken zorluk yaşayabilir. Sadece klinik olarak şüphelenilen olgulara WISC-R uygulanması çalışmamızın kısıtlılıklarından biridir. Çocuk psikiyatrisi kliniklerinde zekâ geriliği olan çocukların ruhsal durum muayeneleri yapılırken çocuğun anlayabileceği basit bir dil ile cinsel istismarın da sorgulanması ve ailelere bu yönde bilgi verilmesi cinsel istismarın zekâ geriliği olan çocuklarda gözden kaçmasını önleyebilir.

Çalışmamızda bedene cinsel amaçla dokunma ve cinsel penetrasyon en sik saptanan istismar tipleri olup, olguların yaklaşık \%65'inde en az bir ruhsal bozukluk saptanmıştır. Çalışmalarda \%71-90 arasında değişen oranlarda cinsel istismar sonrası ruh sağlı̆̆ında bozulma olduğu ve en sı TSSB görüldü̈̆ü bildirilmiştir (12,14,27-30). Bizim çalışmamızda da literatürle uyumlu olarak en sık ruhsal bozukluğun TSSB olduğu bulunmuştur. Uzunlamasına, gözlemsel, karşılaştırmalı 37 çalışmanın dâhil edildiği bir meta-analiz çalışmasında, cinsel istismar öyküsünün, TSSB, depresyon, yeme bozuklukları ve intihar girişimiyle ilişkili olduğu bulunmuştur. Ayrıca önceki çalışmalarda cinsel istismara uğrayan çocuk ve ergenlerin \%10-34 oranları arasında aktif psikopatoloji sergilemedikleri saptanmıştır $(14,31,32)$. Çalışmamızda ise bu oran \%35 olup literatürle uyumlu niteliktedir. İstismara uğramış çocukların yaklaşık 1/3’ü akut dönemde herhangi bir belirti vermeyebilir, takibe dayalı veriler çocukların \%10-20'sinde 12-18 ay içinde ruhsal sorunların başlayabileceğini ortaya koymuştur (2).

Çalışmamızda dikkati çeken bulgulardan biri, 158 çocuk ve ergenden yaklaşık \%31'inin (1/3) ilkokul veya lise terk olmasıdır. Çalışmada yer alan mağdur ergenlerin bir kısmı istismara uğradıktan sonra aileleri tarafından okuldan alındıklarını, bazılar ise kendilerinin okulu bıraktıklarını ifade etmişlerdir. Çalışmalarda da istismara uğrayan ergenlerin şiddet içerikli davranışlara yönelme, intihar davranış1 göstermenin yansıra, okuldan ve evden kaçma gibi davranış sorunlarını da sıklıkla sergilediklerini göstermektedir (33).

Türk Ceza Yasasının 103/6. madde hükmüne göre cinsel istismar suçunu işleyen ve mağdurun beden ve ruh sağlığının bozulmasına sebebiyet veren şüpheli veya hükümlüler suçun ağırlaştırılmış hali oluştuğu için 15 yıldan az olmayan bir ceza 
yaptırımıyla karşı karşıya kalmaktaydılar. Ne var ki; 28 Haziran 2014 tarihinde Resmi Gazetede yayımlanan 6545 Sayılı Yasanın 59. maddesinde yapılan düzenlemeyle bahsi geçen TCK 103/6. fıkrası kaldırılmıştır. Çocukların cinsel istismarı suçundan yargılanan kişilere "mağdur çocuğun beden veya ruh sağlığının bozulması halinde" artık "15 yıldan az olmamak üzere” ceza verilemeyecek, maddenin 1. fikrası uygulanarak 815 yıl arasında ceza verilebilecektir. Diğer takdiri indirim sebepleri ve genelde alt sınırdan hüküm kurulması nedeniyle cezaların çoğu alt sınırdan, yani 8 yıldan verilecektir. İlgili fıkranın kaldırılmasıyla, "mağdur çocuğun beden veya ruh sağlığının bozulması halinde" uygulanacak ceza hükmü kalmadığı için Ceza Yasası'nda bir boşluk oluşmuştur.

Sonuç olarak, örneklem grubumuzun sadece adli makamlar tarafından gönderilen olgulardan oluşması, toplumda istismara uğrayan tüm çocukları yansıtmaması, tanıların konulmasında yapılandırılmış görüşme tekniğinden faydalanılmaması, verilerin dosya üzerinden geriye dönük olarak elde edilmesi, cinsel istismar olgularının ileriye dönüik takip verilerini içermemesi çalışmamızdaki kısıtlılıklardır. Bu alanda toplum temelli, geniş örneklemli, uzunlamasına, karşılaştırmalı çalışmalara ihtiyaç duyulmaktadır. Çocuğun cinsel istismarı konusunda sağlık çalışanları, aile ve okulun bilgi sahibi olması hem istismarın önlenmesi hem de erken tanınıp doğru yaklaşımlarda bulunulması açısından son derece önemlidir.

\section{Kaynaklar}

1. Türkiye'de Çocuk İstismarı ve Aile İçi Şiddet Araştırması Özet Rapor. UNICEF; 2010. Available from: http://atud.org.tr/ kutuphane/unisefrapor.pdf

2. Aktepe E. Çocukluk Çağ 1 Cinsel İstismarı. Psikiyatride Güncel Yaklaşımlar-Current Approaches In Psychiatry. 2009;1(2):95-119. Available from: http://www.scopemed. org/?mno=2012

3. Akço S, Aksel S, Arman AR, Beyazova U, Daglı T. Çocuk istismarı ve ihmali uygulama kitabı. İstanbul: Turk Adli Tip Kurumu-Unicef; 2004.

4. Gültekin G, Ruban C, Akduman B, Korkusuz I. Çocuk ve cinsel istismar. Adli Psikiyatri Dergisi 2006;3(1):9-14. Available from: http://www.terazi.com.tr/makalegoster. aspx?id=519

5. Taner Y, Gökler B. Çocuk istismarı ve ihmali: Psikiyatrik yönleri. Hacettepe Med J 2004;35(2):82-86. Available from: http://www.tip.hacettepe.edu.tr/actamedica/2004/sayi_2/baslik 3.pdf

6. Erdoğan A, Tufan E, Karaman MG, ark v. Türkiye'nin dört farklı bölgesinde çocuk ve ergenlere cinsel tacizde bulunan kişilerin karakteristik özellikleri. Anadolu Psikiyatr Derg 2011;12(1):55-61. Available from: http://www.scopemed. org/?mno=4699

7. Imren SG, Ayaz AB, Yusufoglu C, Arman AR. Clinical Features and Risk Factors Related With Suicide Attempts in Sexually Abused Child and Adolescents. Marmara Medical Journal 2012;2012(11):10-5472. Available from: http:// www.marmaramedicaljournal.org/summary_en_doi.php3?doi=10 .5472/MMJ.2012.02518.1 doi: 10.5472/ MMJ.2012.02518.1.

8. Işeri E. Cinsel istismar. In: Çocuk ve Ergen Psikiyatrisi Temel Kitabı. Ankara: Çocuk ve Gençlik Ruh Sağlığı Derneği Yayınları:3; 2008. p. 470-477.
9. Aktepe E, Işık A, Kocaman O, Eroğlu FO. Demographic and Clinical Characteristics of Children and Adolescents Examined in a University Hospital Who Are Victims of Sexual Abuse. New/Yeni Symposium Journal 2013;51(2):115-120. Available from: http://www.yenisempozyum.net/Pdf/EN-YeniSempozyum6fa77bfa.PDF

10. Kaufman J. Child abuse and neglect. In: Lewis's Child and Adolescent Psychiatry: A Comprehensive Textbook. 4th ed. Martin A, Volkmar FR, editors. 4th ed. Philadelphia: Lippincott Williams \&amp; Wilkins; 2007. p. 693-699.

11. Bernet W. Çocuga kötü muamele. In: Kaplan \& Sadock's Comprehensive Textbook of Psychiatry. Sadock BJ, Sadock VA, Ruiz P, editors. Türkçe, 8. Baskı. Çev. ed,; Aydın H, Bozkurt A,. Ankara: Güneş Kitabevi Ltd; 2007. p. 3412-3425.

12. Öztop DB, Özcan OO. Cinsel İstismar Vakalarının Sosyodemografik ve Klinik Özelliklerinin Değerlendirilmesi, The Sociodemographic and Clinical Evaluation of Sexually Abused Children. New/Yeni Symposium Journal;48(4):270-276. Available from: http://www.yenisempozyum.net/Pdf/TR-YeniSempoz yum-97e2e73a.PDF

13. Karakaya I, Coşkun A, Agaoglu B. Cinsel istismara maruz kaldığı bildirilen olguların ruhsal değerlendirme sonuçları. Adli Tıp Bülteni 2006;11:53-59.

14. Köse S, Aslan Z, Başgül SS, Sahin S, Yılmaz S, Citak S, et al. Bir eğitim ve araştırma hastanesi çocuk psikiyatrisi polikliniğine yönlendirilen adli olgular. Anadolu Psikiyatr Derg 2011;12:221-5. Available from: http://www. scopemed.org/?mno=9296

15. Ayaz M, Ayaz AB, Soylu N. Çocuk ve ergen adli olgularda ruhsal değerlendirme. Klin Psikiyatr Derg 2012;15:33-40. Available from: http://klinikpsikiyatri.org/files/journals/ 1/2952.pdf

16. Dubowitz H. Preventing Child Neglect and Physical Abuse: A Role for Pediatricians. Pediatrics in Review 2002 Jun;23(6):191-196. Available from: http://pedsinreview.aappublications.org/cgi /doi/10.1542/pir.23-6-191 PubMed PMID: 12042593. doi: 10.1542/pir.23-6-191.

17. Fis NP, Arman A, Kalaça S, Berkem M. Psychiatric evaluation of sexual abuse cases: A clinical representative sample from Turkey. Child Youth Serv Rev 2010;32(10): 1285-90. Available from: http://linkinghub. elsevier.com/retrieve/pii /S01907409 10001295 doi: 10.1016/j.childyouth.2010.04. 020.

18. Cöpür M, Uneri OS, Aydın E, Bahalı MK, Tanıdır C, Güneş H, et al. Characteristic features of sexually abused children and adolescents in İstanbul sample. Anadolu Psikiyatri Derg 2012;13(1):46-50. Available from: http://www. scopemed.org/?mno=16413

19. Kucuker H. Analysis of 268 child and adolescent victims of sexual assault and the legal outcome. Turk J Pediatr 2008;50(4):313-316. Available from: http://www.turkishjournalpediatrics. org/?fullTextId=529\&lang=eng PubMed PMID: 19014042.

20. Vural P, Uçar HN, Eray S, Colpan M, Kocael O. Uludağ Üniversitesi Tip Fakültesi Hastanesi Çocuk Psikiyatrisi Polikliniğine Yönlendirilen Adli Olguların Sosyodemografik ve Klinik Özelliklerinin Değerlendirilmesi. 2013;39(1):49-53. Available from: http://uludagtipdergisi.org/pdf/pdf_UTF _373.pdf

21. Bahali K, Akçan R, Tahiroglu AY, Avci A. Child Sexual Abuse: Seven Years in Practice. Journal of Forensic Sciences 2010;55(3):633-636. Available from: http://doi.wiley.com/ 10.1111/j.1556-4029.2010.01357.x PubMed PMID: 20345776. doi: 10.1111/j.1556-4029.2010.01357.x.

22. Anderson J, Martin JUDY, Mullen PAUL, Romans S, Herbison P. Prevalence of Childhood Sexual Abuse Experiences in a Community Sample of Women. Journal of the American Academy of Child \& Adolescent Psychiatry 1993;32(5):911-919. Available from: http://linkinghub.elsevier.com/retrieve/pii/ S0890856709653016 doi: 10.1097/00004583-199309000-00004. 
23. Murray JB. Psychological Profile of Pedophiles and Child Molesters. The Journal of Psychology 2000;134(2):211-224. Available from: http://www.tandfonline.com /doi/abs/10.1080 /00223980009600863 PubMed PMID: 10766112. doi: 10.1080/00223980009600863.

24. Abel GG, Harlow N. The Abel and Harlow child molestation prevention study. Excerpted from the Stop Child Molestation Book. Xlibris. Philadelphia:Xlibris; 2001.

25. Vandiver DM, Kercher G. Offender and victim characteristics of registered female sexual offenders in Texas: a proposed typology of female sexual offenders.. Sex Abuse 2004;16(2):121-137. Available from: http://www.scholaruniverse.com/ncbilinkout?id= 15208897 PubMed PMID: 15208897.

26. Soylu, N, Alpaslan, AH, Ayaz, M, Esenyel, S, Oruç, M. Psychiatric disorders and characteristics of abuse in sexually abused children and adolescents with and without intellectual disabilities. Research in developmental disabilities, 2013;34(12), 4334-4342.

27. Gökçen C, Dursun OB. Bir Eğitim Hastanesi Çocuk Psikiyatri Birimine Gönderilen Adli Olguların İncelenmesi. Düşünen Adam Psikiyatri ve Nörolojik Bilimler Dergisi 2012;25:238-243. Available from: http://www.scopemed. org/?mno=26457

28. Fis NP, Arman A, Kalaca S, Berkem M. Psychiatric evaluation of sexual abuse cases: A clinical representative sample from Turkey. Children and Youth Services Review 2010;32(10):1285-1290. Available from: http://linkinghub. elsevier.com/retrieve/pii/ S0190740910001295 doi: 10.1016/j.childyouth.2010.04.020.
29. Ayaz M, Ayaz AB, Soylu N. Çocuk ve ergen adli olgularda ruhsal değerlendirme. Klin Psikiyatr Derg 2012;15(1):33-40. Available from: http://klinikpsikiyatri.org/files /journals/1/2952.pdf

30. Imren SG, Ayaz AB, Yusufoglu C, Rodopman Arman A. Clinical Features and Risk Factors Related With Suicid Attempts in Sexually Abused Child and Adolescents. MMJ 2013;1(16):11-5472. Available from: http://www.marmaramedicaljournal.org/ summary_en_doi.php3?doi=10.5472/MMJ.2012.02518.1 doi: 10.5472/MMJ.2012.02518.1.

31. Syengo-Mutisya CM, Kathuku DM, Ndetei DM. Psychiatric morbidity among sexually abused children and adolescents.. East Afr Med J 2008;85(2):85-91. Available from: http://www.ajol.info/ index.php/eamj/article/view /9611 PubMed PMID: 18557252. doi: $10.4314 /$ eamj. v85i2.9611.

32. Celik $\mathrm{CB}$, Odaci $\mathrm{H}$. The effect of experience of childhood abuse among university students on self-perception and submissive behavior. Children and Youth Services Review 2002;34(1):200-204. Available from: http://www.sciencedirect.com/science/article /pii/S0190740911003653 doi: 10.1016/j.childyouth.2011.09.017.

33. Soylu N, Alpaslan AH. Suicidal behavior and associated factors in sexually abused adolescents. Children and Youth Services Review 2013;35(2):253-257. Available from: http://linkinghub.elsevier. com/retrieve/pii/S0190740912004057 doi: 10.1016/j.childyouth. 2012.11.002. 